Images du travail, travail des images

$2 \mid 2016$

Les ouvriers et la photographie : de 1945 à nos jours

Shati (Photographie extraite de la série « Les vies brisées du Rana Plaza»)

Jean-François Fort

\title{
OpenEdition
}

Journals

Édition électronique

URL : https://journals.openedition.org/itti/1261

DOI : 10.4000/itti.1261

Éditeur

Université de Poitiers

Référence électronique

Jean-François Fort, "Shati (Photographie extraite de la série "Les vies brisées du Rana Plaza ») ", Images du travail, travail des images [En ligne], 2 | 2016, mis en ligne le 01 septembre 2016, consulté le 24 juillet 2021. URL : http://journals.openedition.org/itti/1261 ; DOI : https://doi.org/10.4000/itti.1261

Ce document a été généré automatiquement le 24 juillet 2021.

Images du travail, travail des images 


\section{Shati (Photographie extraite de la série "Les vies brisées du Rana Plaza »)}

\section{Jean-François Fort}

Shati

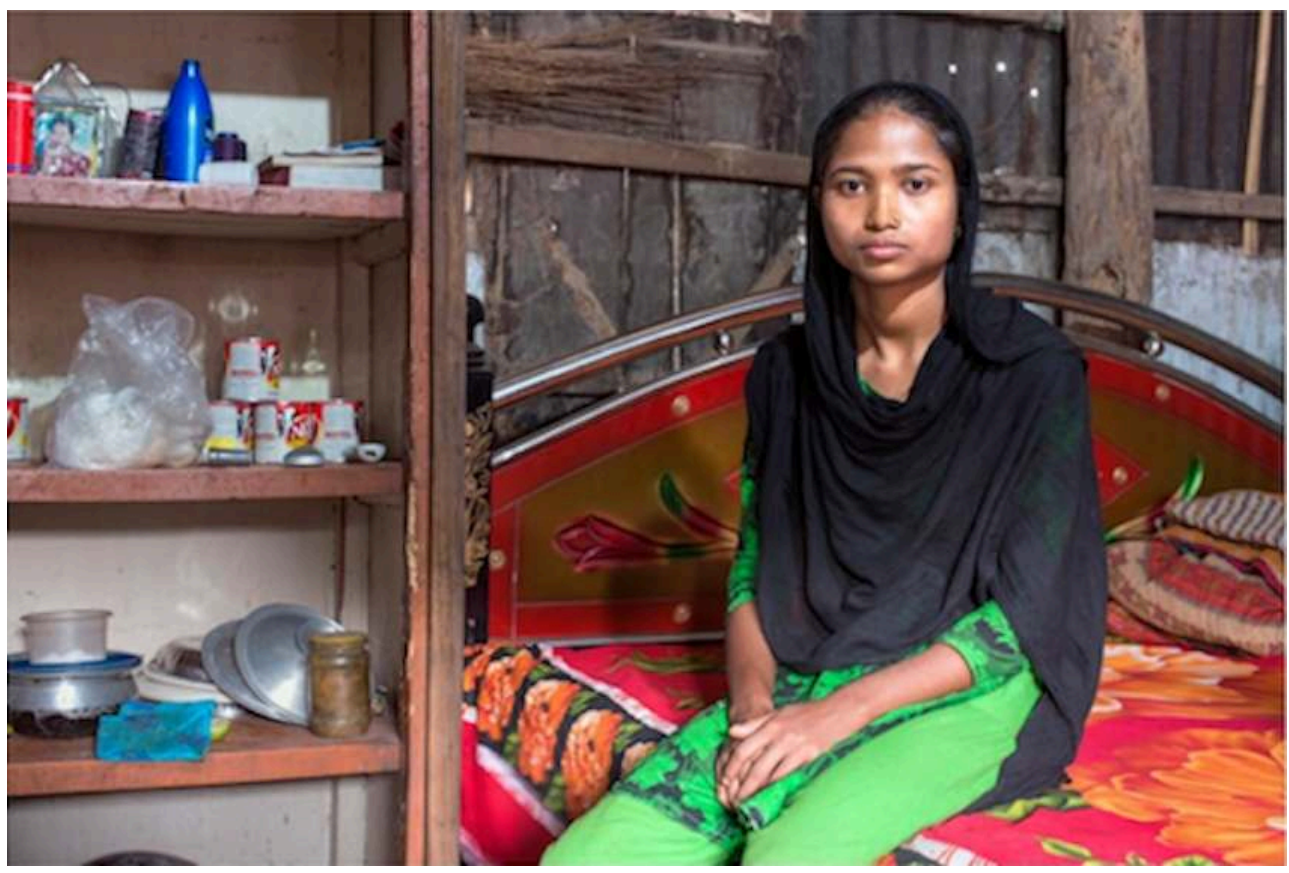

Blessée aux jambes et à la tête, Shati, 21 ans, ne peut rester longtemps debout et ne supporte plus la lumière intense. Elle n'a perçu que l'équivalent de $550 €$ qui sont bloqués sur un compte car elle a perdu la carte lui permettant d'y accéder

(c) Jean-François Fort

Le 24 avril 2013, à Savar dans la banlieue de Dhaka au Bangladesh, le Rana Plaza, immeuble de 7 étages, s'effondre sur des employés du textile, faisant au moins 1138 morts et encore plus de blessés. Près de 100 corps ne seront jamais retrouvés. Ces personnes, comme celles de centaines d'autres ateliers de la capitale, travaillaient pour 
moins de $2 €$ par jour, exploités par leurs employeurs et indirectement par les grands groupes occidentaux trouvant là le moyen d'accroître leurs bénéfices. Même au Bangladesh, un tel salaire ne suffit pas pour vivre.

2 Le gouvernement, des associations, des entreprises étrangères impliquées dans ce drame, essaient aujourd'hui d'améliorer les conditions de travail de ces employés en augmentant les salaires, en contrôlant la sécurité et en tentant de mettre en place des systèmes d'assurances. Il existe cependant des milliers d'ateliers de confection à Dhaka où une main d'œuvre abondante et vulnérable afflue chaque année (300 000 réfugiés climatiques ou économiques par an). La situation est donc difficilement contrôlable.

3 Fin 2015, grâce à l'aide d'une très importante association bangladaise, « Gonoshasthaya Kendra ", plus souvent appelée «GK », j'ai la chance de rencontrer et de photographier une centaine de survivants. Tous ont vécu l'horreur de sentir le monde s'effondrer comme un château de cartes sous leurs pieds et sur leurs têtes aussi. Beaucoup ont été écrasés, broyés par des blocs de béton, des ferrailles, des machines et ont senti la mort très proche. Pendant des jours les secours ont retiré des décombres, rescapés et cadavres. Les indemnités versées par les entreprises étrangères permettront à ceux qui ne peuvent plus travailler de survivre quelques années tout au plus.

Des mois de contacts, de négociations ont été nécessaires pour rencontrer et photographier ces personnes. Je souhaitais qu'elles aient enfin des visages. Choisir une photographie de cette série pour illustrer un article se révèle une épreuve difficile car cela revient à choisir une personne parmi des dizaines d'autres, je le fais avec un certain sentiment de trahison...

5 Shati, 21ans, photographiée ici dans la chambre qu'elle partage avec une autre jeune femme synthétise sans doute les sentiments que j'ai pu éprouver. Jeunesse brisée, rêves envolés et malgré tout la chance d'avoir survécu. Une indemnisation ridicule, que la fatalité rend ici inaccessible. Elle est belle, émouvante, mais quel avenir pour Shati condamnée à vivre avec ses douleurs, ses cauchemars, son incapacité à travailler et à être indépendante ? Cette photographie dévoile toutes ses possessions : un lit qu'elle doit partager et quelques objets de première nécessité sur une étagère. En dépit de sa tristesse, de ses inquiétudes légitimes quant à son avenir, elle ne montre aucune amertume, bien que consciente de l'exploitation dont elle a été et restera victime. Dans cette région du monde où vivre est souvent synonyme de survivre, on n'étale pas ses états d'âmes.

6 Sur le plan photographique, j'ai choisi la neutralité de la couleur et du point de vue : vision frontale "à hauteur d'homme, les yeux dans les yeux ", en veillant à conserver une certaine distance et en évitant tout effet.

7 J'aime à penser que ce travail participera à améliorer son sort comme celui des autres victimes et de leurs proches. Je les remercie de m'avoir confié leur image, les côtoyer a assurément modifié ce que je suis et pour moi, nul besoin de regarder leurs photographies, leurs visages sont maintenant gravés dans ma mémoire.

Site de l'association qui les suit, les soigne et les soutient.

Lien vers le site de son soutien français.

Site de Jean-François Fort 


\section{AUTEUR}

\section{JEAN-FRANÇOIS FORT}

Photographe voyageur, Jean-François Fort explore ce qu'il y a d'universel dans notre humanité, au-delà de toutes frontières et de tous préjugés, à son rythme et sans souci de rentabilité. Tout d'abord inspiré par la littérature de sa jeunesse il a marché sur les pas de Loti, Rimbaud, Kessel, Frison-Roche et bien d'autres. Il se tourne aujourd'hui vers des thèmes plus sociaux comme les derniers cheminots du train Franco-Ethiopien de Dire Daoua en Ethiopie, les victimes du Rana Plaza au Bangladesh ou encore les réfugiés climatiques à Dacca.

En 2013, l'écrivain et artiste Claude Margat écrivait au sujet de son travail :

«Comme l'univers dont il est l'un des aspects, le visage humain reste une énigme que le regard du photographe Jean-François Fort ne cesse d'interroger. Car le visage est bien le lieu et même le seul endroit de la personne humaine où se condense une présence pour nous aussi vague qu'essentielle : l'humanité, la présence de ce qui fait que l'homme possède quelque chose de plus que son frère animal, la présence en sa propre personne d'un questionnement assez vif pour révéler la présence d'un abîme jusqu'alors invisible à nos yeux. »

Site : jeanfrancoisfortphotographies.com 